\title{
Selective Autophagy as a Potential Therapeutic Target in Age-Associated Pathologies
}

\author{
Margarita-Elena Papandreou ${ }^{1,2}$ and Nektarios Tavernarakis $1,2, *$ (D) \\ 1 Institute of Molecular Biology and Biotechnology, Foundation for Research and Technology-Hellas, \\ 70013 Heraklion, Greece; m.papandreou@imbb.forth.gr \\ 2 Department of Basic Sciences, Faculty of Medicine, University of Crete, 70013 Heraklion, Greece \\ * Correspondence: tavernarakis@imbb.forth.gr
}

check for

updates

Citation: Papandreou, M.-E.;

Tavernarakis, N. Selective Autophagy as a Potential Therapeutic Target in Age-Associated Pathologies. Metabolites 2021, 11, 588. https:/ / doi.org/10.3390/metabo11090588

Academic Editor: Ajit Divakaruni

Received: 15 July 2021

Accepted: 27 August 2021

Published: 31 August 2021

Publisher's Note: MDPI stays neutral with regard to jurisdictional claims in published maps and institutional affiliations.

Copyright: (c) 2021 by the authors. Licensee MDPI, Basel, Switzerland. This article is an open access article distributed under the terms and conditions of the Creative Commons Attribution (CC BY) license (https:// creativecommons.org/licenses/by/ $4.0 /)$.

\begin{abstract}
Progressive accumulation of damaged cellular constituents contributes to age-related diseases. Autophagy is the main catabolic process, which recycles cellular material in a multitude of tissues and organs. Autophagy is activated upon nutrient deprivation, and oncogenic, heat or oxidative stress-induced stimuli to selectively degrade cell constituents and compartments. Specificity and accuracy of the autophagic process is maintained via the precision of interaction of autophagy receptors or adaptors and substrates by the intricate, stepwise orchestration of specialized integrating stimuli. Polymorphisms in genes regulating selective autophagy have been linked to aging and age-associated disorders. The involvement of autophagy perturbations in aging and disease indicates that pharmacological agents balancing autophagic flux may be beneficial, in these contexts. Here, we introduce the modes and mechanisms of selective autophagy, and survey recent experimental evidence of dysfunctional autophagy triggering severe pathology. We further highlight identified pharmacological targets that hold potential for developing therapeutic interventions to alleviate cellular autophagic cargo burden and associated pathologies.
\end{abstract}

Keywords: age-related disease; aging; aggrephagy; mitophagy; neurodegeneration; nucleophagy; pexophagy; rapamycin; selective autophagy

\section{Introduction}

Cellular garbage disposal is critical for recycling defective cell constituents, such as proteins and organelles, towards the maintenance of cellular homeostasis. One of the main degradative molecule pathways is autophagy, which is a physiological catabolic process shared by all eukaryotes. Derived from the Greek words 'auto' meaning self, and 'phagy', meaning eating, autophagy, it was initially considered to be a bulk degradation process, while now its highly selective nature is increasingly appreciated. This self-digestive mechanism relieves the cell from proteotoxic, genotoxic, oxidative and nutrient stress [1]. It is accomplished in an intricate stepwise manner, which leads to clearance of damaged cell constituents, in the degradative organelle, the lysosome. Failure to complete this procedure has been implicated in many age-related diseases. Three main types of autophagy have been characterized in detail: macro-autophagy, henceforth referred to as autophagy, which invariably entails the formation of a double membrane vesicle that fuses with the lysosome; micro-autophagy, where there is direct interaction between the autophagic substrate and the lytic organelle, and chaperone-mediated autophagy (CMA), where autophagic substrates are targeted by chaperones and guided to specific receptors on the lysosome, for degradation.

\section{Main Text \\ 2.1. General Autophagy}

Autophagy involves three main, consecutive steps: initiation, elongation and autophagosomal/lysosomal fusion. Although basal autophagy occurs at different levels, 
depending on the tissue, particular stimuli, such as, protein aggregation, DNA damage, reactive oxygen species (ROS), and nutrient deprivation activate or upregulate the autophagic response [2]. Initially, early autophagic structures form, at the pre-autophagosomal site (PAS), where there is nucleation of the initiation membrane, forming the 'moonshaped' phagophore. Expansion of the phagophore leads to PI(3)P-rich omegasome formation, which when sealed, forms the double membrane vesicle, the autophagosome. Although the endoplasmic reticulum is the main site for autophagosome formation, ERmitochondria/plasma membranes contact sites, the plasma membrane itself, the Golgi complex, and recycling endosomes have emerged as autophagosomal biogenesis sites $[3,4]$.

The ULK1 (Unc-51-like kinase 1) and PIKC3-C1 signaling complexes are activated during autophagic induction [5]. Physiologically, phosphorylated ULK1 and ATG13 are inactive and bound to mTORC1 (master cell growth regulator). During amino acid starvation, ULK1 is dephosphorylated and released from mTORC1, which in turn activates ATG13 and FIP200 [6]. Moreover, TFEB is disinhibited upon starvation to upregulate autophagy genes, as well as, lysosomal and lipid catabolism [7]. Next, phagophore expansion involves ATG8 family proteins, which are cleaved by the ATG4 protease at their C-terminus, and then lipidated. Activation of lipidated ATG8s is performed by ATG7 with the aid of ATG5-ATG12. This activity is localized at the phagophore by ATG16L, ultimately leading to phagophore expansion. However, the requirement for ATG8 lipidation for autophagosome assembly has been recently challenged [8].

During autophagosome maturation, the autophagosomal membrane is targeted to the lysosomal membrane by ATGs, the cytoskeleton, mainly microtubule-related kinesins, and the fusion machinery. The fusion machinery comprises SNAREs, both on the autophagosomal, syntaxin 17 (STX17), synaptosomal-associated protein (SNAP29) and lysosomal membrane (VAMP8), with the aid of the homotypic fusion and protein sorting (HOPS) complex, for membrane tethering during fusion $[9,10]$.

\subsection{Selective Autophagy}

Selective autophagy degrades a plethora of autophagic cargo, which is targeted upon specific cellular insults. Defective mitochondria (mitophagy), protein aggregates (aggrephagy) or pathogenic bacteria (xenophagy) are selective autophagy triggers. Atg8 proteins interact and recruit selective autophagic receptors, which contain LIR (LC3interacting) motifs (W/F/Y-X-X-L/I/V), with upstream negatively charged residues for higher affinity interactions, as well as, post-translational modifications, such as phosphorylation [11]. These receptors are recruited upon induction of selective autophagy, which is, in turn, directed to specific autophagic substrates by other tags, such as K27-linked mono-or K63 poly-ubiquitination events. Autophagic receptors such as p62, NBR1 (a neighbor of BRCA1 gene 1), OPTN1 (optineurin) contain both LIR and UBA binding motifs [12]. ULK1 controls selective autophagy independently of mTOR. Recent evidence suggests that ULK1 interaction with huntingtin is required for activation. Subsequently, huntingtin aids the LC3-p62-autophagic cargo interaction [13,14].

\subsubsection{Mitophagy and Aging}

Homeostatic mechanisms that respond to mitochondrial damage are less efficient during aging. Mitophagy is a physiological eukaryotic pathway, which involves the degradation of superfluous or damaged mitochondria [15]. When perturbed, normal mitochondrial function is hindered, resulting in the production of excessive ROS [16]. This ultimately leads to cellular dysfunction and tissue damage.

A multitude of mitophagic regulators and receptors have been identified that are cargo content and stress-dependent. Phosphatase and tensin homologue (PTEN)-induced putative kinase 1 (PINK1) and 1-E3 ubiquitin ligase Parkin-mediated mitophagy is the predominant type of autophagic degradation of mitochondria. Under non mitophagyinducing conditions, PINK is transferred to the inner mitochondrial membrane, where it is cleaved by proteases and subsequently degraded by the proteasome $[17,18]$. Upon 
membrane depolarization, PINK1 phosphorylation and Parkin-mediated ubiquitination of outer mitochondrial membrane proteins initiates a series of intricate events, which ultimately leads to autophagic machinery recruitment, for whole mitochondria degradation [17]. In addition, PINK1 indirectly activates dynamin-related protein 1 (DRP1), which in turn promotes fission of defective mitochondria to facilitate mitochondrial autophagic degradation [19].

Although Parkin-dependent mitophagy accounts for a large percentage of mitochondrial recycling, there are other Parkin-independent pathways that involve different ubiquitin ligases. These enzymes generate ubiquitin chains to recruit autophagic adaptors such as optineurin (OPTN), nuclear dot protein 52 (NDP52) and p62, which directly interact with LC3 through their LIRs [14,15]. Moreover, core autophagic components such as the Unc51-like autophagy activating kinase 1, (ULK1) and the double FYVE-domain containing protein 1 (DFCP1), are also localized close to mitochondria to alleviate mitoaggregation [20]. Outer mitochondrial membrane proteins can act as mitophagy receptors themselves, during cellular homeostasis, differentiation and hypoxia, specifically, NIX (NIP3-like protein X), BNIP3 (BCL2 interacting protein 3) and FUNDC1 (FUN14 domain-containing protein) [21-23]. Importantly, NIX and BNIP3 regulate Parkin recruitment, highlighting the interplay between the PINK1-Parkin pathway and mitophagy receptors [24].

Defective mitophagy is evident in a variety of age-related pathologies such as neurodegeneration, metabolic syndromes and myopathies (Figure 1) [25]. In Alzheimer's disease (AD), PINK1 expression is extremely low, while mitochondrial numbers and oxidative stress increase [26]. Mutations in PINK1/Parkin have been identified in familial Parkinson's disease, while overexpression of NIX upregulates mitophagy in PINK1/Parkin deficient neurons [27]. Mutations the homologues of these proteins cause decreased lifespan, dopaminergic neuronal death and muscle atrophy, in Drosophila [28]. Defective mitophagy has also been found to induce autoimmune responses, in a cell non autonomous manner. In the absence of PINK1/Parkin, immune cells trigger an immune response by expressing MHC-class I at their plasma membrane [29]. Additionally, retinal ganglion cell axons have been shown to extrude their mitochondria that are then degraded by neighboring astrocytes [30]. In Huntington's disease, mutant huntingtin appears to perturb mitophagic function [31]. Mitophagy is also essential for cardiac function, and protects against high fat diet, diabetic induced, cardiomyopathy [32]. Recently, PINK1 and parkin have also been associated with mitochondrial genome mutations; mitophagic levels are inversely proportional to mitochondrial DNA mutations especially in neurons [33].

With regard to therapeutic intervention, several pharmacological compounds have been shown to activate mitophagy and alleviate symptoms of age-related diseases, dependent on dysfunctional mitochondria. Similar to aggrephagy, rapamycin activates AMPK, while blocking mTOR, maintaining energetic demands and preventing neurological symptoms, such as neuroinflammation $[34,35]$. Metformin and pifithrin induce Parkin by inhibiting p53 activity and alleviating diabetic phenotypes [36-38]. Resveratrol, mainly found in grape skin, as well as, NAD+ precursors found in natural compounds activate mitophagy and mitochondrial biogenesis through the sirtuin 1 (SIRT1)-PGC-1 $\alpha$ axis [39,40]. Urolithin A, an intestinal microbiome-derived metabolite from dietary intake, induces both mitochondrial degradation and biogenesis, and increases health span of model organisms such as C. elegans and mice (Table 1) [41].

\subsubsection{Aggrephagy and Age-Related Disease}

Aggrephagy degrades aggregation-prone proteins via targeted macro-autophagy, in addition to CMA and the proteasomal pathway. These proteins typically form aggresomes near the nucleus, which are surrounded by intermediate filament cytoskeleton, and are further processed to be degraded by autophagy. Protein aggregation usually occurs due to misfolding and can cause, among others, dysregulation of calcium homeostasis, inflammation, neurotoxicity [42]. Normal $\lambda y$, in unstressed cells, the proteasome is the main degradative pathway for ubiquitin-tagged proteins; however, protein aggregation and over- 
load requires activation of autophagy [1]. Specific neurodegenerative diseases represent prominent examples of dysfunctional aggrephagy. In AD, Parkinson's disease, amyotrophic lateral sclerosis and polyglutamine diseases, autophagy is perturbed (Figure 1) [43,44]. In the context of these pathologies, defective proteins accumulate in aggresomes, which are identified by their ubiquitination status and the selective autophagic receptor $\mathrm{p} 62$, for autophagosomal targeting [45].

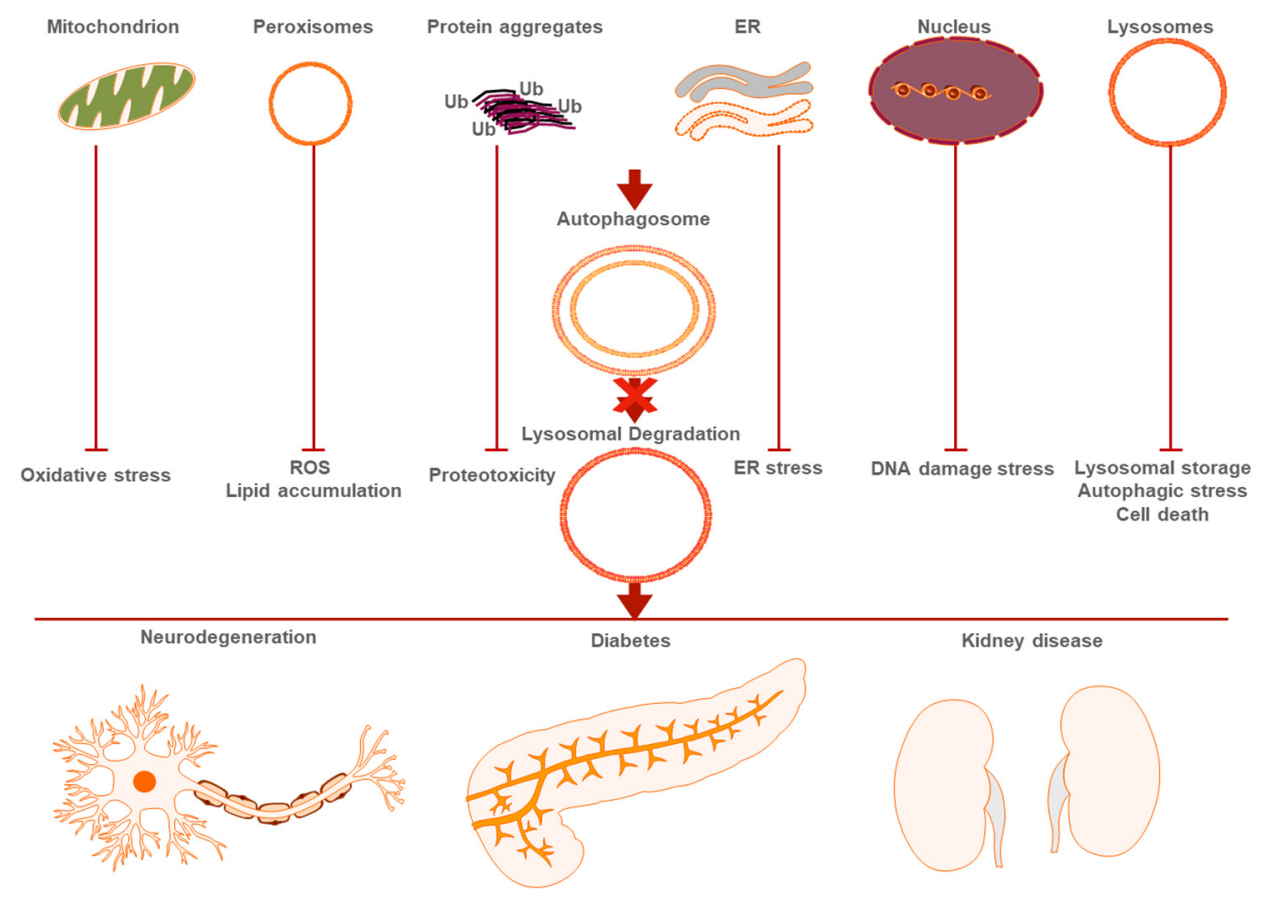

Figure 1. Perturbation of selective autophagy triggers age-related disease. Autophagic degradation of organelles (mitochondria, peroxisomes, ER, nuclei, lysosomes) and protein aggregates leads to loss of cellular homeostasis and subsequent pathological conditions.

Pharmacological compounds, which can upregulate autophagy, with the aim of ameliorating pathology in neurodegenerative diseases, have been identified. In AD, amyloid-beta aggregates in oligomers, autophagy is defective and synapse formation and function are perturbed. The size and solubility of aggregates determines the extent of cellular toxicity effects [46]. AVN-211, Lu AE58054, SB-742457 which are antagonists of the mTOR activator, 5-HT6R, significantly delay memory impairment in AD, with the second reaching Phase III clinical trials, while the latter reaching Phase II, but eventually failing to show the expected efficacy (Table 1) [47-49]. Recently, alborixin was identified as an autophagy inducer in both neuronal and glial cells, through the upregulation of several autophagic mediators such as Beclin-1, ATG5 and ATG7, by inhibiting the AKT pathway [50]. Oral administration of a recombinant $A A V / A \beta$, which alleviated $A \beta$ overload, was also found to activate autophagy [51]. Moreover, rapamycin inhibits mTOR, while resveratrol activates AMPK to induce autophagy. The latter has reached Phase III trial [52]. Lithium, which is used in psychiatric disorder treatments, acts via GSK- $3 \beta$ inhibition to delay cognitive decline [53]. AUTEN-67, an inhibitor of MTMR14, which is antagonistic to autophagosome membrane formation, promotes autophagy, longevity and prevents neuronal cell death, in both in vitro and in vivo AD and Huntington's disease models [54]. Nicotinamide, which enhances autophagosome/autolysosome acidification, promotes autophagic flux and, hence, ameliorates AD pathology, in mouse disease models [55].

In PD, Beclin 1 gene transfer and overexpression of TFEB have been shown to increase degradation of $\alpha$-synuclein, and generate promising therapeutic results in mouse models [56,57]. Interestingly, curcumin, prevents oxidative stress and inflammation, while blocking $\alpha$-synuclein aggregation [58]. The NRF2 activator, dimethyl fumarate (DMF), 
already used for treatment of multiple sclerosis, was shown to alleviate $\alpha$-synuclein toxicity [59]. In polyglutamine disorders, mutant forms of several proteins such as ataxin-1 and huntingtin contain expanded polyglutamine repeats, which are cleared out by autophagy [60]. Notably, mutant huntingtin perturbs autophagy, aggravating general protein and microRNA regulator Argonaute 2 clearance defects, causing global dysregulation of miRNA expression [61]. Similarly to AD, AUTEN-67 and rapamycin have been shown to have therapeutic effects in PD animal experimental models [62]. Moreover, trehalose and calpastatin have been shown to alleviate symptoms in rodent models, with calpastatin acting as a calpain inhibitor and activator of autophagy $[63,64]$. Nevertheless, translational efforts aiming to bring these research results to the clinic have been met with limited success.

\subsubsection{Pexophagy and Aging}

Recycling of peroxisomes is also regulated by autophagy. These small dynamic single membrane organelles regulate fatty acid oxidation, production of bile acid and other lipids, while also producing reactive oxygen species (ROS), which is neutralized by catalase [65]. Moreover, peroxisomes interact with a multitude of other cellular constituents, such as lipids, the ER and mitochondria [66]. Peroxisome biogenesis can be stimulated by oleic acid, methanol or amines in different yeast species $[67,68]$. In addition, pexophagy is triggered by feeding yeast with peroxisome-independent carbon sources, while it is inhibited when long fatty acids are abundant [69]. In mammals, ubiquitin acts as a tag for peroxisomal proteins, such as PEX3 and PEX5, that are then recognized by autophagic receptors, including p62 and NBR1, initiating peroxisome lysosomal degradation [70,71]. The PEX2-PEX10-PEX-12 complex functions as an E3 ubiquitin ligase that mediates PEX5 receptor recycling. Depletion of the PEX2-PEX10-PEX-12 complex abrogates starvationinduced pexophagy [72].

Pexophagy and peroxisome biogenesis have recently been implicated with disease. During aging, peroxisomal targeting signal 1 (PTS1) protein import deteriorates and catalase function is diminished. Peroxisomes become more abundant and PEX5 accumulates on their membranes. This causes increased production of ROS, which further blocks peroxisomal protein import and contributes to aging (Figure 1) [73]. Additionally, catalase is gradually excluded from peroxisomes, during cellular senescence [74]. Increased ROS production is a common denominator of perturbations in both peroxisomal recycling and mitophagy, during aging [75]. However, specific induction of intraperoxisomal ROS production causes mitochondrial fragmentation, while catalase inhibition disturbs mitochondrial redox potential. Peroxisome dysfunction may precede mitochondrial dysfunction in certain age-related diseases [76]. Moreover, recent high throughput mass spectrometry analyses showed that 30 peroxisomal proteins decrease with age in C. elegans [77].

Post-mortem analysis of Parkinson's disease patient brains showed a reduction in polyunsaturated fatty acid content, including DHA and arachidonic acid, with concomitant increase in saturated fatty acids, compared to healthy controls. Peroxisomal lipids such as cholesterol are reduced in PD, while its oxidized derivatives correlate with PD pathogenesis and progression. Drugs regulating cholesterol levels appear to alleviate PD symptoms (Table 1). Ethanolamine plasmalogens are undetectable in the blood and brain of PD patients, while supplementation with PPI-1011, which is an ethanolamine plasmalogen precursor, reduces dopamine neuron loss in a PD mouse model [78-80].

\subsubsection{Nucleophagy and Nuclear Alterations in Aging}

Autophagic recycling of the nucleus, or nucleophagy, entails the degradation of multiple compartments of the nucleus, from parts of the nucleolus to the nuclear lamina [81]. Nucleophagy has been described in the context of cancer and neurodegeneration, both of which are also age-associated pathologies.

In yeast, nucleophagy is triggered physiologically, under nutrient stress. Autophagic cargo includes the granular nucleolus, which is targeted by the micro-autophagy receptor Nvj1 and the macro-autophagy receptor Atg39 [82]. Nucleolar size has been established as 
an accurate aging biomarker in C. elegans and mammals. Fibrillarin is a major component of the nucleolus, and a nucleolar marker. Notably, reduction of fibrillarin levels causes nucleolar contraction, and extends lifespan, in worms [83]. By contrast, increasing fibrillarin expression, through inhibition of the fibrillarin translational repressor NCL-1, shortens animal lifespan. Remarkably, long-lived C. elegans mutants, such as daf-2 and eat-2, display smaller nucleoli, compared to wild type controls. These long-lived mutant animals are also characterized by higher levels of general and cargo-specific autophagy. Genetic downregulation of autophagy in these mutants abrogates their longevity. Consistently, in Drosophila, pharmacological induction of autophagy by rapamycin reduces nucleolar size in the intestine and fat body [84]. These findings outline an intricate relationship between autophagy, nucleolar size, and longevity.

While nucleophagy has not been directly implicated in aging, severe nuclear envelope and nucleoplasm alterations are observed in old animals. Aged nematodes display nuclear loss or decreased DNA copy number in the intestine [85]. Nucleophagy has also been observed under oncogenic stress, where nuclear LC3 directly interacts with the LIR motif of lamin B. Both LC3 and lamin B are then transported together in the cytoplasm for lysosomal degradation [86]. Oncogenic stress is aggravated during aging. Nucleophagy may serve as a mechanism for damage mitigation in this context. Indeed, lamins accumulate in premature aging syndromes [87]. In addition, damaged DNA that progressively accumulates during aging is recycled through autophagy and the lysosomal enzyme Dnase2a (Figure 1) [88]. Thus, this type of nucleophagy could protect against DNA damage, which directly contributes to aging.

In addition to cancer, nuclear lamina degradation has been implicated in neurodegenerative diseases, such as ataxias, which are characterized by defects in several types of autophagy. In a mouse model of dentatorubral-pallidoluysian atrophy (DRPLA), a polyglutamine repeat-associated ataxia, canonical autophagy is inhibited, while nucleophagybased Lamin B1 degradation and Golgi membrane-associated excretion is activated [89]. Thus, hijacking of the autophagic machinery causes nuclear defects that lead to cell atrophy and death. This is an example of nuclear lamina recycling deregulation, leading to exacerbated nucleophagy and neurodegeneration.

\subsubsection{Other Types of Selective Autophagy in Age-Related Disease}

ER-phagy is the selective degradation of parts of the endoplasmic reticulum that contributes to the maintenance of ER homeostasis and recovery after ER stress [90]. Specific receptors of ER-phagy have been identified, including FAM134B, SEC62, RTN3L, CCPG1, ATL3 and TEX264. Lesions in FAM134B impair its autophagic receptor function, facilitating, stress-induced apoptosis and degeneration of sensory neurons, which causes severe sensory and autonomic neuropathy [91,92]. Polymorphisms in this gene have been also associated with vascular dementia [93]. Moreover, ER-phagy was recently shown to degrade mutant NPC1, a protein involved in intracellular lipid trafficking, which has been implicated in Niemann-Pick type C, a fatal neurodegenerative disease, [94]. In addition, ATL3 protects sensory neurons by regulating ER membrane-forming proteins, in the absence of which, axonal degeneration ensues [95]. Furthermore, RTN3 deficiency further aggravates amyloid- $\beta$ deposition, in an AD mouse model [96]. However, the mechanistic association of ERphagy with the aging process itself is not well-understood.

Lysosomal disintegration occurs during aging. Apart from blocking the breakdown of cellular compartments, defects in lysophagy, the recycling of lysosomes; can activate diverse cell death pathways such as apoptosis, necroptosis, pyroptosis and ferroptosis [97]. Notably, in AD lysosomal pH is elevated, impairing the function of the organelle [98]. Moreover, lysosomal cathepsin D activity is required for efficient clearance of $\alpha$-synuclein in Parkinsons' disease [99]. Several potential pharmacological compounds which modulate lysophagy have been shown to ameliorate metabolic disorders, such as, diabetes and associated kidney disease (Table 1) [100-106]. 
Table 1. Association of selective autophagy inducers with disease therapy or aging.

\begin{tabular}{|c|c|c|c|c|}
\hline $\begin{array}{c}\text { Autophagy } \\
\text { Inducer }\end{array}$ & $\begin{array}{c}\text { Type of } \\
\text { Autophagy }\end{array}$ & Disease/Aging & Organism & Reference \\
\hline Pifithrin & Mitophagy & Diabetes, PD & Mouse & [35] \\
\hline Metformin & Mitophagy & Diabetes, PD & Mouse, Human & [36] \\
\hline Urolithin A & Mitophagy & Aging & Mouse & [40] \\
\hline SB-742457 & Aggrephagy & $\mathrm{AD}$ & Human & [46] \\
\hline Lu AE58-54 & Aggrephagy & $\mathrm{AD}$ & Human & [47] \\
\hline AVN-211 & Aggrephagy & $\mathrm{AD}$ & Mouse & [48] \\
\hline rAAV & Aggrephagy & $\mathrm{AD}$ & Mouse, Rat & [50] \\
\hline Resveratrol & $\begin{array}{l}\text { Mitophagy, } \\
\text { Aggrephagy } \\
\text { Lysophagy }\end{array}$ & $\begin{array}{l}\text { AD, Diabetic } \\
\text { kidney disease }\end{array}$ & Human & {$[38,51,99]$} \\
\hline Rapamycin & $\begin{array}{l}\text { Mitophagy, } \\
\text { Aggrephagy }\end{array}$ & $\mathrm{AD}$ & Mouse & {$[34,51]$} \\
\hline Lithium & Aggrephagy & $\mathrm{AD}$ & Human & [52] \\
\hline Nicotinamide & Aggrephagy & $\mathrm{AD}$ & Human & [54] \\
\hline DMF & Aggrephagy & PD & Mouse & [58] \\
\hline Curcumin & $\begin{array}{l}\text { Aggrephagy, } \\
\text { Lysophagy }\end{array}$ & PD, Diabetes & Mouse, Rat & {$[57,104]$} \\
\hline $\begin{array}{c}\text { Beclin-1 and } \\
\text { TFEB } \\
\text { overexpression }\end{array}$ & Aggrephagy & PD & Mouse & {$[55,56]$} \\
\hline AUTEN-67 & Aggrephagy & $\begin{array}{c}\text { AD, PD, } \\
\text { Huntington's } \\
\text { disease }\end{array}$ & Mouse & {$[53,61]$} \\
\hline Trehalose & Aggrephagy & PD & Mouse & [62] \\
\hline Calpastatin & Aggrephagy & PD & Mouse & [63] \\
\hline PPI-1011 & Pexophagy & PD & Mouse & [78] \\
\hline Catalase & Lysophagy & $\begin{array}{c}\text { Diabetic kidney } \\
\text { disease }\end{array}$ & Human & [100] \\
\hline Tubastatin A & Lysophagy & $\begin{array}{c}\text { Diabetic kidney } \\
\text { disease }\end{array}$ & Rat & [101] \\
\hline Torin 1 & Lysophagy & Diabetes & Mouse & [102] \\
\hline Tocopherol & Lysophagy & Diabetes & Rat & [103] \\
\hline
\end{tabular}

\section{Conclusions}

Extensive research has revealed the direct association of selective autophagy defects and age-related disease. Initially thought to be non-selective, autophagy was considered to be a highly promising therapeutic target. Diseases associated with physiological aging such as neurodegeneration and metabolic disorders are the outcome of genetic inhibition of selective autophagy, which also declines physiologically during aging. Experimental evidence is increasingly showing the significance of autophagic degradation in maintaining organismal homeostasis, particularly in highly specialized tissues such as the nervous system. The intricacy and crosstalk of these selective autophagic pathways raises the challenge of combinatorial drug treatment.

Selective autophagic induction by genetic intervention or chemical compound administration is currently being investigated in multiple diseases as potential therapeutic approach, although no drug has reached the clinic yet. Indeed, clinical studies concerning druggable autophagy targets, remains limited. This highlights the complexity and intricacies of selective autophagic pathways, which in humans, cannot be easily targeted due to context-dependence and extensive crosstalk with other functional networks. Thus, initial optimism has subsided, with research now focusing on specific compounds that could target specific aspects of selective autophagy. An important objective of the collective efforts of the research community and pharmaceutical companies is to achieve targeting selective autophagy mediators, while not affecting other cellular processes. This would be 
an imperative step, minimizing adverse consequences to organismal physiology, towards clinical trials in human patients.

Author Contributions: Writing-original draft preparation, M.-E.P. \& N.T.; writing-review and editing, M.-E.P. \& N.T.; funding acquisition, N.T. All authors have read and agreed to the published version of the manuscript.

Funding: Work in the authors' laboratory was funded by grants from the European Research Council (ERC), the European Commission Framework Programs, and the Greek Ministry of Education. M.E.P. was supported by the ERC Advanced Investigator Grant "MANNA".

Institutional Review Board Statement: Not applicable.

Informed Consent Statement: Not applicable.

Data Availability Statement: Not applicable.

Conflicts of Interest: The authors declare no conflict of interest.

\section{References}

1. Dikic, I. Proteasomal and autophagic degradation systems. Annu. Rev. Biochem. 2017, 86, 193-224. [CrossRef]

2. Papandreou, M.-E.; Tavernarakis, N. Tavernarakis, Nucleophagy mediators and mechanisms. Prog. Mol. Biol. Transl. Sci. 2020, $172,1-14$.

3. Hamasaki, M.; Furuta, N.; Matsuda, A.; Nezu, A.; Yamamoto, A.; Fujita, N.; Oomori, H.; Noda, T.; Haraguchi, T.; Hiraoka, Y.; et al. Autophagosomes form at ER-mitochondria contact sites. Nature 2013, 495, 389-393. [CrossRef]

4. Nascimbeni, A.C.; Giordano, F.; Dupont, N.; Grasso, D.; Vaccaro, M.I.; Codogno, P.; Morel, E. ER-plasma membrane contact sites contribute to autophagosome biogenesis by regulation of local PI3P synthesis. EMBO J. 2017, 36, 2018-2033. [CrossRef]

5. Karanasios, E.; Stapleton, E.; Manifava, M.; Kaizuka, T.; Mizushima, N.; Walker, S.; Ktistakis, N.T. Dynamic association of the ULK1 complex with omegasomes during autophagy induction. J. Cell Sci. 2013, 126, 5224-5238. [CrossRef]

6. Hosokawa, N.; Hara, T.; Kaizuka, T.; Kishi, C.; Takamura, A.; Miura, Y.; Iemura, S.-I.; Natsume, T.; Takehana, K.; Yamada, N.; et al. Nutrient-dependent mTORC1 association with the ULK1-Atg13-FIP200 complex required for autophagy. Mol. Biol. Cell 2009, 20, 1981-1991. [CrossRef]

7. Settembre, C.; Fraldi, A.; Medina, D.L.; Ballabio, A. Signals from the lysosome: A control centre for cellular clearance and energy metabolism. Nat. Rev. Mol. Cell Biol. 2013, 14, 283-296. [CrossRef]

8. Tsuboyama, K.; Koyama-Honda, I.; Sakamaki, Y.; Koike, M.; Morishita, H.; Mizushima, N. The ATG conjugation systems are important for degradation of the inner autophagosomal membrane. Science 2016, 354, 1036-1041. [CrossRef] [PubMed]

9. Itakura, E.; Kishi-Itakura, C.; Mizushima, N. The hairpin-type tail-anchored SNARE syntaxin 17 targets to autophagosomes for fusion with endosomes/lysosomes. Cell 2012, 151, 1256-1269. [CrossRef] [PubMed]

10. Diao, J.; Liu, R.; Rong, Y.; Zhao, M.; Zhang, J.; Lai, Y.; Zhou, Q.; Wilz, L.M.; Li, J.; Vivona, S.; et al. ATG14 promotes membrane tethering and fusion of autophagosomes to endolysosomes. Nature 2015, 520, 563-566. [CrossRef] [PubMed]

11. Richter, B.; Sliter, D.A.; Herhaus, L.; Stolz, A.; Wang, C.; Beli, P. Phosphorylation of OPTN by TBK1 enhances its binding to Ub chains and promotes selective autophagy of damaged mitochondria. Proc. Natl. Acad. Sci. USA 2016, 113, 4039-4044. [CrossRef]

12. Lamark, T.; Kirkin, V.; Dikic, I.; Johansen, T. NBR1 and p62 as cargo receptors for selective autophagy of ubiquitinated targets. Cell Cycle 2009, 8, 1986-1990. [CrossRef] [PubMed]

13. Rui, Y.; Xu, Z.; Patel, B.; Chen, Z.; Chen, D.; Tito, A.; David, G.; Sun, Y.; Stimming, E.F.; Bellen, H.; et al. Huntingtin functions as a scaffold for selective macroautophagy. Nat. Cell Biol. 2015, 17, 262-275. [CrossRef]

14. Lazarou, M.; Sliter, D.A.; Kane, L.A.; Sarraf, S.; Wang, C.; Burman, J.L.; Sideris, D.P.; Fogel, A.I.; Youle, R.J. The ubiquitin kinase PINK1 recruits autophagy receptors to induce mitophagy. Nature 2015, 524, 309-314. [CrossRef]

15. Palikaras, K.; Lionaki, E.; Tavernarakis, N. Mechanisms of mitophagy in cellular homeostasis, physiology and pathology. Nat. Cell Biol. 2018, 20, 1013-1022. [CrossRef]

16. Gatica, D.; Lahiri, V.; Klionsky, D.J. Cargo recognition and degradation by selective autophagy. Nat. Cell Biol. 2018, 20, 233-242. [CrossRef]

17. Harper, J.W.; Ordureau, A.; Heo, J.-M. Building and decoding ubiquitin chains for mitophagy. Nat. Rev. Mol. Cell Biol. 2018, 19, 93-108. [CrossRef] [PubMed]

18. Sekine, S.; Youle, R.J. PINK1 import regulation; a fine system to convey mitochondrial stress to the cytosol. BMC Biol. 2018, 16, 2. [CrossRef] [PubMed]

19. Pryde, K.R.; Smith, H.L.; Chau, K.; Schapira, A. PINK1 disables the anti-fission machinery to segregate damaged mitochondria for mitophagy. J. Cell Biol. 2016, 213, 163-171. [CrossRef] [PubMed]

20. Hsieh, C.W.; Yang, W.Y. Omegasome-proximal PtdIns(4,5)P2 couples F-actin mediated mitoaggregate disassembly with autophagosome formation during mitophagy. Nat. Commun. 2019, 10, 969. [CrossRef] 
21. Quinsay, M.N.; Thomas, R.L.; Lee, Y.; Gustafsson, B. Bnip3-mediated mitochondrial autophagy is independent of the mitochondrial permeability transition pore. Autophagy 2010, 6, 855-862. [CrossRef] [PubMed]

22. Liu, L.; Feng, D.; Chen, G.; Chen, M.; Zheng, Q.; Song, P.; Ma, Q.; Zhu, C.; Wang, R.; Qi, W.; et al. Mitochondrial outer-membrane protein FUNDC1 mediates hypoxia-induced mitophagy in mammalian cells. Nat. Cell Biol. 2012, 14, 177-185. [CrossRef]

23. Esteban-Martínez, L.; Sierra-Filardi, E.; McGreal, R.S.; Salazar-Roa, M.; Mariño, G.; Seco, E.; Durand, S.; Enot, D.; Graña, O.; Malumbres, M.; et al. Programmed mitophagy is essential for the glycolytic switch during cell differentiation. EMBO J. 2017, 36, 1688-1706. [CrossRef]

24. Ding, W.X.; Ni, H.M.; Li, M.; Liao, Y.; Chen, X.; Stolz, D.B. Nix is critical to two distinct phases of mitophagy, reactive oxygen species-mediated autophagy induction and Parkin-ubiquitin-p62-mediated mitochondrial priming. J. Biol. Chem. 2010, 285, 27879-27890. [CrossRef] [PubMed]

25. Palikaras, K.; Daskalaki, I.; Markaki, M.; Tavernarakis, N. Mitophagy and age-related pathologies: Development of new therapeutics by targeting mitochondrial turnover. Pharmacol. Ther. 2017, 178, 157-174. [CrossRef] [PubMed]

26. Manczak, M.; Kandimalla, R.; Yin, X.; Reddy, P.H. Hippocampal mutant APP and amyloid beta-induced cognitive decline, dendritic spine loss, defective autophagy, mitophagy and mitochondrial abnormalities in a mouse model of Alzheimer's disease. Hum. Mol. Genet. 2018, 27, 1332-1342. [CrossRef] [PubMed]

27. Koentjoro, B.; Park, J.-S.; Sue, C.M. Nix restores mitophagy and mitochondrial function to protect against PINK1/Parkin-related Parkinson's disease. Sci. Rep. 2017, 7, 44373. [CrossRef]

28. Yang, Y.; Gehrke, S.; Imai, Y.; Huang, Z.; Ouyang, Y.; Wang, J.; Yang, L.; Beal, M.F.; Vogel, O.H.; Lu, B. Mitochondrial pathology and muscle and dopaminergic neuron degeneration caused by inactivation of Drosophila Pink1 is rescued by Parkin. Proc. Natl. Acad. Sci. USA 2006, 103, 10793-10798. [CrossRef] [PubMed]

29. Matheoud, D.; Sugiura, A.; Bellemare-Pelletier, A.; Laplante, A.; Rondeau, C.; Chemali, M.; Fazel, A.; Bergeron, J.J.; Trudeau, L.-E.; Burelle, Y.; et al. Parkinson's disease-related proteins PINK1 and parkin repress mitochondrial antigen presentation. Cell 2016, 166, 314-327. [CrossRef]

30. Davis, C.-H.O.; Kim, K.-Y.; Bushong, E.A.; Mills, E.A.; Boassa, D.; Shih, T.; Kinebuchi, M.; Phan, S.; Zhou, Y.; Bihlmeyer, N.; et al. Transcellular degradation of axonal mitochondria. Proc. Natl. Acad. Sci. USA 2014, 111, 9633-9638. [CrossRef] [PubMed]

31. Sun, N.; Yun, J.; Liu, J.; Malide, D.; Liu, C.; Rovira, I.I.; Holmström, K.; Fergusson, M.M.; Yoo, Y.H.; Combs, C.A.; et al. Measuring In Vivo Mitophagy. Mol. Cell 2015, 60, 685-696. [CrossRef] [PubMed]

32. Tong, M.; Saito, T.; Zhai, P.; Oka, S.-I.; Mizushima, W.; Nakamura, M.; Ikeda, S.; Shirakabe, A.; Sadoshima, J. Mitophagy is essential for maintaining cardiac function during high fat diet-induced diabetic cardiomyopathy. Circ. Res. 2019, 124, 1360-1371 [CrossRef]

33. Ahier, A.; Dai, C.-Y.; Kirmes, I.; Cummins, N.; Hung, G.C.C.; Götz, J.; Zuryn, S. PINK1 and parkin shape the organism-wide distribution of a deleterious mitochondrial genome. Cell Rep. 2021, 35, 109203. [CrossRef] [PubMed]

34. Johnson, S.C.; Yanos, M.E.; Kayser, E.-B.; Quintana, A.; Sangesland, M.; Castanza, A.; Uhde, L.; Hui, J.; Wall, V.Z.; Gagnidze, A.; et al. mTOR inhibition alleviates mitochondrial disease in a mouse model of Leigh syndrome. Science 2013, 342, 1524-1528. [CrossRef]

35. Kim, J.; Yang, G.; Kim, Y.; Kim, J.; Ha, J. AMPK activators: Mechanisms of action and physiological activities. Exp. Mol. Med. 2016, 48, e224. [CrossRef]

36. Hoshino, A.; Ariyoshi, M.; Okawa, Y.; Kaimoto, S.; Uchihashi, M.; Fukai, K. Inhibition of p53 preserves Parkin-mediated mitophagy and pancreatic beta-cell function in diabetes. Proc. Natl. Acad. Sci. USA 2014, 111, 3116-3121. [CrossRef] [PubMed]

37. Song, Y.M.; Lee, W.K.; Lee, Y.-H.; Kang, E.S.; Cha, B.-S.; Lee, B.-W. Metformin restores parkin-mediated mitophagy, suppressed by cytosolic p53. Int. J. Mol. Sci. 2016, 17, 122. [CrossRef]

38. Bhansali, S.; Bhansali, A.; Dutta, P.; Walia, R.; Dhawan, V. Metformin upregulates mitophagy in patients with T2DM: A randomized placebo-controlled study. J. Cell. Mol. Med. 2020, 24, 2832-2846. [CrossRef]

39. Lagouge, M.; Argmann, C.; Gerhart-Hines, Z.; Meziane, H.; Lerin, C.; Daussin, F.; Messadeq, N.; Milne, J.; Lambert, P.; Elliott, P.; et al. Resveratrol improves mitochondrial function and protects against metabolic disease by activating SIRT1 and PGC-1 $\alpha$. Cell 2006, 127, 1109-1122. [CrossRef] [PubMed]

40. Georgakopoulos, N.D.; Wells, G.; Campanella, N.D.G.M. The pharmacological regulation of cellular mitophagy. Nat. Chem. Biol. 2017, 13, 136-146. [CrossRef]

41. Andreux, P.A.; Blanco-Bose, W.; Ryu, D.; Burdet, F.; Ibberson, M.; Aebischer, P.; Auwerx, J.; Singh, A.; Rinsch, C. The mitophagy activator urolithin $\mathrm{A}$ is safe and induces a molecular signature of improved mitochondrial and cellular health in humans. Nat. Metab. 2019, 1, 595-603. [CrossRef] [PubMed]

42. Malampati, S.; Song, J.-X.; Tong, B.C.-K.; Nalluri, A.; Yang, C.-B.; Wang, Z.; Sreenivasmurthy, S.G.; Zhu, Z.; Liu, J.; Su, C.; et al. Targeting aggrephagy for the treatment of alzheimer's disease. Cells 2020, 9, 311. [CrossRef] [PubMed]

43. Gan-Or, Z.; Dion, P.A.; Rouleau, G.A. Genetic perspective on the role of the autophagy-lysosome pathway in Parkinson disease. Autophagy 2015, 11, 1443-1457. [CrossRef]

44. Moors, T.; Paciotti, S.; Chiasserini, D.; Calabresi, P.; Parnetti, L.; Beccari, T.; van de Berg, W.D. Lysosomal dysfunction and alpha-synuclein aggregation in parkinson's disease: Diagnostic links. Mov. Disord. 2016, 31, 791-801. [CrossRef]

45. Pankiv, S.; Clausen, T.H.; Lamark, T.; Brech, A.; Bruun, J.A.; Outzen, H. p62/SQSTM1 binds directly to Atg8/LC3 to facilitate degradation of ubiquitinated protein aggregates by autophagy. J. Biol. Chem. 2007, 282, 24131-24145. [CrossRef] 
46. De, S.; Wirthensohn, D.C.; Flagmeier, P.; Hughes, C.; Aprile, F.A.; Ruggeri, F.S. Different soluble aggregates of Abeta42 can give rise to cellular toxicity through different mechanisms. Nat. Commun. 2019, 10, 1541. [CrossRef]

47. Maher-Edwards, G.; Zvartau-Hind, M.; Hunter, A.; Gold, M.; Hopton, G.; Jacobs, G.; Davy, M.; Williams, P. Double-blind, controlled phase II study of a 5-HT6 receptor antagonist, SB-742457, in Alzheimer's disease. Curr. Alzheimer Res. 2010, 7, 374-385. [CrossRef] [PubMed]

48. Wilkinson, D.; Windfeld, K.; Colding-Jorgensen, E. Safety and efficacy of idalopirdine, a 5-HT6 receptor antagonist, in patients with moderate Alzheimer's disease (LADDER): A randomised, double-blind, placebo-controlled phase 2 trial. Lancet Neurol. 2014, 13, 1092-1099. [CrossRef]

49. Ivachtchenko, A.V.; Lavrovsky, Y.; Ivanenkov, Y.A. AVN-211, Novel and highly selective 5-HT6 receptor small molecule antagonist, for the treatment of alzheimer's disease. Mol. Pharm. 2016, 13, 945-963. [CrossRef]

50. Wani, A.; Gupta, M.; Ahmad, M.; Shah, A.M.; Ahsan, A.U.; Qazi, P.H. Alborixin clears amyloid-beta by inducing autophagy through PTEN-mediated inhibition of the AKT pathway. Autophagy 2019, 15, 1810-1828. [CrossRef]

51. Vingtdeux, V.; Giliberto, L.; Zhao, H.; Chandakkar, P.; Wu, Q.; Simon, J.E. Autophagy is involved in oral rAAV/Abeta vaccineinduced Abeta clearance in APP/PS1 transgenic mice. Neurosci. Bull. 2015, 31, 491-504.

52. Forlenza, O.V.; De-Paula VD, J.R.; Diniz BS, O. AMP-activated protein kinase signaling activation by resveratrol modulates amyloid-beta peptide metabolism. J. Biol. Chem. 2010, 285, 9100-9113.

53. Forlenza, O.V.; De-Paula, V.J.; Diniz, B.S. Neuroprotective effects of lithium: Implications for the treatment of Alzheimer's disease and related neurodegenerative disorders. ACS Chem. Neurosci. 2014, 5, 443-450. [CrossRef] [PubMed]

54. Liu, D.; Pitta, M.; Jiang, H.; Lee, J.H.; Zhang, G.; Chen, X. AUTEN-67, an autophagy-enhancing drug candidate with potent antiaging and neuroprotective effects. Autophagy 2016, 12, 273-286.

55. Liu, D.; Pitta, M.; Jiang, H.; Lee, J.H.; Zhang, G.; Chen, X. Nicotinamide forestalls pathology and cognitive decline in Alzheimer mice: Evidence for improved neuronal bioenergetics and autophagy procession. Neurobiol. Aging 2013, 34, 1564-1580. [CrossRef] [PubMed]

56. Spencer, B.; Potkar, R.; Trejo, M.; Rockenstein, E.; Patrick, C.; Gindi, R. Beclin 1 gene transfer activates autophagy and ameliorates the neurodegenerative pathology in alpha-synuclein models of Parkinson's and Lewy body diseases. J. Neurosci. 2009, 29, 13578-13588. [CrossRef] [PubMed]

57. Decressac, M.; Mattsson, B.; Weikop, P.; Lundblad, M.; Jakobsson, J.; Bjorklund, A. TFEB-mediated autophagy rescues midbrain dopamine neurons from alpha-synuclein toxicity. Proc. Natl. Acad. Sci. USA 2013, 110, E1817-E1826. [CrossRef] [PubMed]

58. Ji, H.F.; Shen, L. The multiple pharmaceutical potential of curcumin in Parkinson's disease. CNS Neurol. Disord. Drug Targets 2014, 13, 369-373. [CrossRef] [PubMed]

59. Lastres-Becker, I.; García-Yagüe, A.J.; Scannevin, R.H.; Casarejos, M.J.; Kügler, S.; Rábano, A.; Cuadrado, A. Repurposing the NRF2 activator dimethyl fumarate as therapy against synucleinopathy in parkinson's disease. Antioxid. Redox Signal. 2016, 25, 61-77. [CrossRef]

60. Iwata, A.; Christianson, J.C.; Bucci, M.; Ellerby, L.M.; Nukina, N.; Forno, L.S.; Kopito, R.R. Increased susceptibility of cytoplasmic over nuclear polyglutamine aggregates to autophagic degradation. Proc. Natl. Acad. Sci. USA 2005, 102, 13135-13140. [CrossRef]

61. Pircs, K.; Petri, R.; Madsen, S.; Brattås, P.L.; Vuono, R.; Ottosson, D.R. Huntingtin aggregation impairs autophagy, leading to Argonaute-2 accumulation and global MicroRNA dysregulation. Cell Rep. 2018, 24, 1397-1406. [CrossRef]

62. Billes, V.; Kovács, T.; Hotzi, B.; Manzéger, A.; Tagscherer, K.; Komlós, M.; Tarnóci, A.; Pádár, Z.; Erdős, A.; Bjelik, A.; et al. AUTEN-67 (Autophagy Enhancer-67) Hampers the Progression of Neurodegenerative Symptoms in a Drosophila model of Huntington's Disease. J. Huntingt. Dis. 2016, 5, 133-147. [CrossRef]

63. Sarkar, S.; Rubinsztein, D.C. Huntington's disease: Degradation of mutant huntingtin by autophagy. FEBS J. 2008, 275, 4263-4270. [CrossRef] [PubMed]

64. Menzies, F.M.; Garcia-Arencibia, M.; Imarisio, S.; O'Sullivan, N.; Ricketts, T.H.; Kent, B.; Rao, M.; Lam, W.; Green-Thompson, Z.W.; Nixon, R.A.; et al. Calpain inhibition mediates autophagy-dependent protection against polyglutamine toxicity. Cell Death Differ. 2015, 22, 433-444. [CrossRef] [PubMed]

65. Lazarow, P.B.; De Duve, C. A fatty acyl-CoA oxidizing system in rat liver peroxisomes; enhancement by clofibrate, a hypolipidemic drug. Proc. Natl. Acad. Sci. USA 1976, 73, 2043-2046. [CrossRef]

66. Germain, K.; Kim, P.K. Pexophagy: A model for selective autophagy. Int. J. Mol. Sci. 2020, 21, 578. [CrossRef]

67. Kunau, W.H.; Hartig, A. Peroxisome biogenesis in Saccharomyces cerevisiae. Antonie Van Leeuwenhoek 1992, 62, 63-78. [CrossRef]

68. Tuttle, D.L.; Lewin, A.; Dunn, W.A. Selective autophagy of peroxisomes in methylotrophic yeasts. Eur. J. Cell Biol. 1993, 60, 283-290. [PubMed]

69. Grygiel-Górniak, B. Peroxisome proliferator-activated receptors and their ligands: Nutritional and clinical implications-A review. Nutr. J. 2014, 13, 17. [CrossRef]

70. Yamashita, S.-I.; Abe, K.; Tatemichi, Y.; Fujiki, Y. The membrane peroxin PEX3 induces peroxisome-ubiquitination-linked pexophagy. Autophagy 2014, 10, 1549-1564. [CrossRef]

71. Deosaran, E.; Larsen, K.B.; Hua, R.; Sargent, G.; Wang, Y.; Kim, S.; Lamark, T.; Jauregui, M.; Law, K.; Lippincott-Schwartz, J.; et al. NBR1 acts as an autophagy receptor for peroxisomes. J. Cell Sci. 2012, 126, 939-952. [CrossRef]

72. Sargent, G.; Van Zutphen, T.; Shatseva, T.; Zhang, L.; Di Giovanni, V.; Bandsma, R.; Kim, P.K. PEX2 is the E3 ubiquitin ligase required for pexophagy during starvation. J. Cell Biol. 2016, 214, 677-690. [CrossRef] 
73. Legakis, J.E.; Koepke, J.I.; Jedeszko, C.; Barlaskar, F.; Terlecky, L.J.; Edwards, H.J.; Walton, P.A.; Terlecky, S.R. Peroxisome Senescence in Human Fibroblasts. Mol. Biol. Cell 2002, 13, 4243-4255. [CrossRef] [PubMed]

74. Cipolla, C.M.; Lodhi, I.J. Peroxisomal dysfunction in age-related diseases. Trends Endocrinol. Metab. 2017, 28, 297-308. [CrossRef]

75. Fransen, M.; Nordgren, M.; Wang, B.; Apanasets, O.; Van Veldhoven, P.P. Aging, Age-Related Diseases and Peroxisomes. Mol. Biol. Cell 2013, 69, 45-65.

76. Ivashchenko, O.; Van Veldhoven, P.P.; Brees, C.; Ho, Y.-S.; Terlecky, S.R.; Fransen, M. Intraperoxisomal redox balance in mammalian cells: Oxidative stress and interorganellar cross-talk. Mol. Biol. Cell 2011, 22, 1440-1451. [CrossRef] [PubMed]

77. Narayan, V.; Ly, T.; Pourkarimi, E.; Murillo, A.B.; Gartner, A.; Lamond, A.; Kenyon, C. Deep Proteome Analysis Identifies Age-Related Processes in C. elegans. Cell Syst. 2016, 3, 144-159. [CrossRef]

78. Doria, M.; Maugest, L.; Moreau, T.; Lizard, G.; Vejux, A. Contribution of cholesterol and oxysterols to the pathophysiology of Parkinson's disease. Free Radic. Biol. Med. 2016, 101, 393-400. [CrossRef] [PubMed]

79. Miville-Godbout, E.; Bourque, M.; Morissette, M.; Al-Sweidi, S.; Smith, T.; Mochizuki, A.; Senanayake, V.; Jayasinghe, D.; Wang, L.; Goodenowe, D.; et al. Plasmalogen Augmentation Reverses Striatal Dopamine Loss in MPTP Mice. PLoS ONE 2016, 11, e0151020. [CrossRef] [PubMed]

80. Jo, D.S.; Park, N.Y.; Cho, D.-H. Peroxisome quality control and dysregulated lipid metabolism in neurodegenerative diseases. Exp. Mol. Med. 2020, 52, 1486-1495. [CrossRef] [PubMed]

81. Papandreou, M.E.; Tavernarakis, N. Nucleophagy: From homeostasis to disease. Cell Death Differ. 2019, 26, 630-639. [CrossRef] [PubMed]

82. Mostofa, M.G.; Rahman, M.A.; Koike, N.; Yeasmin, A.M.; Islam, N.; Waliullah, T.M. CLIP and cohibin separate rDNA from nucleolar proteins destined for degradation by nucleophagy. J. Cell Biol. 2018, 217, 2675-2690. [CrossRef]

83. Zlotorynski, E. Ageing: Live longer with small nucleoli. Nat. Rev. Mol. Cell Biol. 2017, 18, 651. [CrossRef]

84. Tiku, V.; Jain, C.; Raz, Y.; Nakamura, S.; Heestand, B.; Liu, W. Small nucleoli are a cellular hallmark of longevity. Nat. Commun. 2017, 8, 16083. [CrossRef]

85. Golden, T.R.; Beckman, K.B.; Lee, A.H.J.; Dudek, N.; Hubbard, A.; Samper, E.; Melov, S. Dramatic age-related changes in nuclear and genome copy number in the nematode Caenorhabditis elegans. Aging Cell 2007, 6, 179-188. [CrossRef] [PubMed]

86. Dou, Z.; Xu, C.; Donahue, G.; Shimi, T.; Pan, J.-A.; Zhu, J.; Ivanov, A.; Capell, B.C.; Drake, A.M.; Shah, P.P.; et al. Autophagy mediates degradation of nuclear lamina. Nature 2015, 527, 105-109. [CrossRef] [PubMed]

87. Cenni, V.; Capanni, C.; Mattioli, E.; Schena, E.; Squarzoni, S.; Bacalini, M.G.; Garagnani, P.; Salvioli, S.; Franceschi, C.; Lattanzi, G. Lamin A involvement in ageing processes. Ageing Res. Rev. 2020, 62, 101073. [CrossRef]

88. Lan, Y.Y.; Londoño, D.; Bouley, R.; Rooney, M.S.; Hacohen, N. Dnase2a deficiency uncovers lysosomal clearance of damaged nuclear DNA via autophagy. Cell Rep. 2014, 9, 180-192. [CrossRef]

89. Baron, O.; Boudi, A.; Dias, C.; Schilling, M.; Nölle, A.; Vizcay-Barrena, G. Stall in canonical autophagy-lysosome pathways prompts nucleophagy-based nuclear breakdown in neurodegeneration. Curr. Biol. 2017, 27, 3626-3642.e6. [CrossRef]

90. Hubner, C.A.; Dikic, I. ER-phagy and human diseases. Cell Death Differ. 2020, 27, 833-842. [CrossRef]

91. Kurth, I.; Pamminger, T.; Hennings, J.C.; Soehendra, D.; Huebner, A.K.; Rotthier, A.; Baets, J.; Senderek, J.; Topaloglu, H.; Farrell, S.A.; et al. Mutations in FAM134B, encoding a newly identified Golgi protein, cause severe sensory and autonomic neuropathy. Nat. Genet. 2009, 41, 1179-1181. [CrossRef] [PubMed]

92. Khaminets, A.; Heinrich, T.; Mari, M.; Grumati, P.; Huebner, A.K.; Akutsu, M.; Liebmann, L.; Stolz, A.; Nietzsche, S.; Koch, N.; et al. Regulation of endoplasmic reticulum turnover by selective autophagy. Nature 2015, 522, 354-358. [CrossRef] [PubMed]

93. Kong, M.; Kim, Y.; Lee, C. A strong synergistic epistasis between FAM134B and TNFRSF19 on the susceptibility to vascular dementia. Psychiatr. Genet. 2011, 21, 37-41. [CrossRef] [PubMed]

94. Schultz, M.; Krus, K.L.; Kaushik, S.; Dang, D.; Chopra, R.; Qi, L.; Shakkottai, V.G.; Cuervo, A.M.; Lieberman, A.P. Coordinate regulation of mutant NPC1 degradation by selective ER autophagy and MARCH6-dependent ERAD. Nat. Commun. 2018, 9, 1-13. [CrossRef] [PubMed]

95. Kornak, U.; Mademan, I.; Schinke, M.; Voigt, M.; Krawitz, P.; Hecht, J.; Barvencik, F.; Schinke, T.; Gießelmann, S.; Beil, F.T.; et al. Sensory neuropathy with bone destruction due to a mutation in the membrane-shaping atlastin GTPase 3. Brain 2014, 137, 683-692. [CrossRef]

96. Shi, Q.; Ge, Y.; Sharoar, G.; He, W.; Xiang, R.; Zhang, Z.; Hu, X.; Yan, R. Impact of RTN3 Deficiency on Expression of BACE1 and Amyloid Deposition. J. Neurosci. 2014, 34, 13954-13962. [CrossRef]

97. Zhu, S.-Y.; Yao, R.-Q.; Li, Y.-X.; Zhao, P.-Y.; Ren, C.; Du, X.-H.; Yao, Y.-M. Lysosomal quality control of cell fate: A novel therapeutic target for human diseases. Cell Death Dis. 2020, 11, 1-13. [CrossRef]

98. Coffey, E.; Beckel, J.; Laties, A.; Mitchell, C. Lysosomal alkalization and dysfunction in human fibroblasts with the Alzheimer's disease-linked presenilin 1 A246E mutation can be reversed with cAMP. Neuroscience 2014, 263, 111-124. [CrossRef]

99. Qiao, L.; Hamamichi, S.; Caldwell, K.; Caldwell, G.; Yacoubian, T.A.; Wilson, S.; Xie, Z.-L.; Speake, L.D.; Parks, R.; Crabtree, D.; et al. Lysosomal enzyme cathepsin D protects against alpha-synuclein aggregation and toxicity. Mol. Brain 2008, 1, 17. [CrossRef]

100. Chougala, M.B.; Bhaskar, J.J.; Rajan, M.; Salimath, P.V. Effect of curcumin and quercetin on lysosomal enzyme activities in streptozotocin-induced diabetic rats. Clin. Nutr. 2012, 31, 749-755. [CrossRef] [PubMed] 
101. Liu, W.J.; Gan, Y.; Huang, W.F.; Wu, H.-L.; Zhang, X.; Zheng, H.J.; Liu, H.-F. Lysosome restoration to activate podocyte autophagy: A new therapeutic strategy for diabetic kidney disease. Cell Death Dis. 2019, 10,1-17. [CrossRef] [PubMed]

102. Brijmohan, A.S.; Batchu, S.N.; Majumder, S.; Alghamdi, T.A.; Thieme, K.; McGaugh, S.; Liu, Y.; Advani, S.L.; Bowskill, B.B.; Kabir, M.G.; et al. HDAC6 Inhibition Promotes Transcription Factor EB Activation and Is Protective in Experimental Kidney Disease. Front. Pharmacol. 2018, 9, 34. [CrossRef]

103. Zhao, Y.; Zhang, W.; Jia, Q.; Feng, Z.; Guo, J.; Han, X.; Liu, Y.; Shang, H.; Wang, Y.; Liu, W.J. Advanced glycation end-products suppress autophagic flux in podocytes by activating mammalian target of rapamycin and inhibiting nuclear translocation of transcription factor EB. J. Pathol. 2018, 245, 235-248. [CrossRef]

104. Zhao, X.; Chen, Y.; Tan, X.; Zhang, L.; Zhang, H.; Li, Z. High dose vitamin E attenuates diabetic nephropathy via alleviation of autophagic stress. Front. Physiol. 2018, 9, 1939. [CrossRef]

105. Liu, W.J.; Shen, T.T.; Chen, R.H.; Wu, H.-L.; Wang, Y.J.; Deng, J.K.; Chen, Q.H.; Pan, Q.; Fu, C.-M.H.; Tao, J.-L.; et al. AutophagyLysosome Pathway in Renal Tubular Epithelial Cells Is Disrupted by Advanced Glycation End Products in Diabetic Nephropathy. J. Biol. Chem. 2015, 290, 20499-20510. [CrossRef] [PubMed]

106. Zheng, H.J.; Zhang, X.; Guo, J.; Zhang, W.; Ai, S.; Zhang, F.; Wang, Y.; Liu, W.J. Lysosomal dysfunction-induced autophagic stress in diabetic kidney disease. J. Cell Mol. Med. 2020, 24, 8276-8290. [CrossRef] [PubMed] 